\title{
DIFERENTES ENFOQUES SOBRE O CONTROLE E A AUTONOMIA DA ATIVIDADE TECNOLÓGICA NO CAPITALISMO ATUAL
}

\section{Thales Novaes de Andrade*}

\begin{abstract}
Resumo: O artigo pretende discutir o tema da autonomia e do controle externo exercido sobre os técnicos no mundo contemporâneo. Essa questão vem mobilizando a atenção de uma série de autores de diferentes áreas. A Sociologia do Trabalho desde Marx tem discutido a crise do gesto técnico atrelada à complexificação dos sistemas produtivos. A Economia da Inovação aponta os impasses que os sistemas econômicos enfrentam à medida que a esfera dos técnicos tem que se submeter aos parâmetros organizacionais. Por sua vez, a Sociologia da Ciência tem disponibilizado diversas reflexões a respeito das transformações do campo científico e os desafios que técnicos e experts enfrentam na busca de autonomização de suas práticas de atuação. Os filósofos das técnicas adentram nesse debate indicando uma ampliação do sistema tecnológico misturada com crise do gesto técnico. Ao cabo, a intenção é mostrar as proximidades dessas correntes no entendimento dos problemas enfrentados pelos agentes técnicos.
\end{abstract}

Palavras-chave: técnicos; cientistas; autonomia; inovação; campo científico; gesto técnico.

\section{Introdução}

A questão tecnológica é central no mundo contemporâneo. Devido a isso, cientistas e técnicos são setores chave em nossa sociedade, pois, mediante suas atividades, novas possibilidades econômicas e culturais podem ser desenvolvidas. O presente

\footnotetext{
Doutor em Ciências Sociais pela Universidade Estadual de Campinas (Unicamp), docente do Departamento de Ciências Sociais da Universidade Federal de São Carlos (UFSCar) e co-editor da revista Teoria \& Pesquisa (ISSN: 0104-0103).E-mail: thales@ufscar.br.
}

Artigo produzido graças a auxílio financeiro do CNPq.

Artigo recebido em 27 jan. 2009 e aprovado em 10 jul. 2009. 
artigo pretende discutir o problema da autonomia que os técnicos usufruem na sociedade atual, e como eles são capazes de conviver com sistemas tecnológicos mais abrangentes e burocratizados, e o que isso significa em termos de aperfeiçoamento de modalidades de controle.

A discussão sobre a burocratização da ciência e tecnologia marcou o pensamento sociológico nos anos 60 e 70, chamando a atenção para o caráter gerencial e formalizado do mundo técnico no capitalismo avançado (Habermas, 1983; Martins, 1974). A tecnocracia representa uma junção entre acumulação, ciência e prática tecnológica, formando um modo de produção em que o principal meio produtivo torna-se o conhecimento, que passa a ser controlado por frações de classe hegemônicas que disputam espaço na burocracia estatal.

A partir de um enfoque diferente, a abordagem neoschumpeteriana insistiu em articular a problemática da inovação tecnológica com a otimização das práticas econômicas e os arranjos produtivos. $\mathrm{O}$ desenvolvimento econômico se articula à tecnologia no interior de uma lógica instrumental e adaptativa (Freeman, 1975), desarticulada da configuração de regimes e sistemas políticos.

Outro aspecto que se sobressai nessa discussão sobre a posição da tecnologia no mundo contemporâneo é a dimensão administrativa e gerencial. O desenvolvimento técnico deve submeter-se às novas modalidades de gestão e aos imperativos do processo produtivo, respeitando estritamente os planejamentos estratégicos e os indicadores de desempenho. Hoje, todo um aparato jurídico e organizacional é criado em torno das práticas de inovação tecnológica, em que os gestores e investidores dividem espaço com os inventores e técnicos (Andrade, 2007).

A condição de autonomia dos técnicos e das práticas tecnológicas, perante a uma burocratização contínua da ciência 
e tecnologia, representa, portanto, um grande desafio. Em que medida é possível aos responsáveis diretos pela pesquisa científica e tecnológica estabelecerem os rumos do progresso técnico? Na atual agenda de inovação, o que predomina: atividades voltadas para o aprimoramento das práticas de gestão e o alcance de metas, ou a contínua experimentação, com menor interferência administrativa e financeira? Em diversas áreas, a condição de desenvolvedores e implementadores tecnológicos está sendo reavaliada por diversos estudos (Lojkine, 1995). Este artigo procurará trazer alguns aspectos dessa discussão e mapear as tendências expressas em diferentes correntes teóricas. Em um primeiro momento será discutido como a Sociologia do Trabalho tem enfocado o papel dos técnicos e pesquisadores em face das transformações tecnológicas do capitalismo. Depois, retomaremos aspectos dessa discussão nos autores ligados à Economia da Inovação, de corte schumpeteriano e articulado à Economia do Conhecimento, as abordagens desse tema pela Sociologia da Ciência e, por último, as reflexões desenvolvidas pela Filosofia Contemporânea das Técnicas.

Essas áreas apresentam especificidades e semelhanças interessantes, e, ao final desse percurso teórico, espera-se lançar bases para uma discussão renovada sobre a relação entre o gesto técnico e o gerenciamento da criação técnica na esfera inovativa, e mostrar as possíveis aproximações entre áreas tradicionalmente distintas.

\section{A posição dos técnicos no sistema capitalista}

A bem da verdade, esse é um tema antigo no pensamento sociológico. No capítulo XIII do volume 1 de O Capital, "Maquinaria e Grande Indústria", Marx discute as transformações da fábrica moderna e o posicionamento da expertise técnica. Ele mostra de forma extremamente elucidativa como a maquinaria foi desenvolvida de modo a atender a interesses capitalistas, e não o contrário. 
As mudanças no fuso e na máquina de fiar foram sendo incorporadas para dar sustentação a orientações produtivas e a ritmos de trabalho alheios ao funcionamento e à concatenação das máquinas. E o estabelecimento de hierarquias entre operários e supervisores, para muito além de uma necessidade técnica, são dispositivos funcionais para a manutenção de uma disciplina produtiva. À medida que o sistema fabril se desenvolve e complexifica, o gesto do operário e a intervenção dos técnicos se empobrecem. Essa é uma das grandes contradições que o sistema fabril instaura sobre a realidade técnica, um misto de avanço tecnológico e econômico sem precedentes, ao preço da banalização generalizada da intervenção técnica.

\begin{abstract}
A separação entre as potências espirituais do processo de produção e o trabalho manual, bem como a transformação das mesmas em poderes do capital sobre o trabalho, se completa ...na grande indústria erguida sobre a base da maquinaria. A habilidade pormenorizada do operador de máquina individual, esvaziado, desaparece como algo ínfimo e secundário perante a ciência, perante enormes forças da Natureza e do trabalho social em massa que estão corporificadas no sistema de máquinas. (Marx, 1985, p. 44).
\end{abstract}

Marx, profundo conhecedor das técnicas de seu tempo, formulou análises que podem não soar muito originais nos dias de hoje, mas têm o mérito de articular a configuração técnica da grande indústria com os imperativos capitalistas. A leitura de seus textos inviabiliza a manutenção de argumentos deterministas, que buscam estabelecer avanço técnico como motor das mudanças sociais (ver a esse respeito Rosenberg, 2006).

Um aspecto central de seu argumento reside na percepção - inédita no seu tempo e de grande atualidade -, que o sistema fabril revolucionou tanto a produção como a atividade técnica no momento em que transformou as ferramentas de trabalho em máquinas-ferramenta. Isso significou o distanciamento humano das práticas de reconfiguração técnica e uma incapacidade dos técnicos em interferir soberanamente nos infinitos percursos possíveis. 
Outro aspecto decisivo, segundo Marx, foi o desenvolvimento de máquinas para construir máquinas. Com isso, a indústria moderna conseguiu dar um salto à frente em relação à manufatura, que foi fundamental. As habilidades humanas, as decisões profissionais e as convicções particulares sofrem uma interdição profunda no contexto produtivo e no interior da prática tecnológica.

A construção de máquinas por máquinas tornou a autonomia de técnicos e cientistas uma ficção, pois tanto o processo de trabalho como a atividade tecnológica são decompostos em uma série de etapas que se sucedem mecanicamente, a despeito da multiplicidade de possibilidades de intervenções e reprogramações.

A grande indústria teve [...] de apoderar-se de seu meio característico de produção, a própria máquina, e produzir máquinas por meio de máquinas. Só assim ela criou sua base técnica adequada e se firmou sobre seus próprios pés. (Marx, 1985, p. 16).

$\mathrm{O}$ autômato se transforma em pleno sujeito, enquanto que operários e técnicos vêem seu virtuosismo e habilidades cerceados e domesticados. O conhecimento empírico precisa se subordinar aos imperativos das rotinas industriais, uma vez que o sistema técnico abarca um sem número de questões que escapam à lógica dos inventores e supervisores técnicos.

Correntes da Sociologia do Trabalho dos anos 60 e 70 levaram adiante o projeto de diagnosticar a relação entre desenvolvimento tecnológico e crise da autonomia dos portadores do gesto técnico. $\mathrm{O}$ argumento central reside em que, no capitalismo avançado, ocorre uma diferenciação entre a classe operária e os trabalhadores qualificados, como técnicos, engenheiros e cientistas. E essa diferenciação pode fornecer uma maior capacidade decisória para os trabalhadores encarregados de tarefas de gerenciamento e supervisão técnica.

No século XX, à medida que as empresas internalizam setores de pesquisa e desenvolvimento (P\&D) para dar suporte a 
atividades concorrenciais, cientistas e técnicos passam a desfrutar de uma legitimidade crescente dentro da economia industrial e suas atividades se descolam daquelas realizadas pelos operários comuns. Eles formam uma camada privilegiada, detentores de uma capacidade de iniciativa e condução de projetos que os torna imprescindíveis para o desempenho de firmas e laboratórios a elas atrelados (Mallet, 1963).

Essa corrente de pensamento, que prevê um aburguesamento tendencial de setores da classe trabalhadora por vias de um domínio de qualificações técnicas e científicas, defende que o desenvolvimento, nas áreas de química e metalurgia principalmente, levaria a uma diferenciação interna das empresas. Isso geraria um privilégio dos profissionais mais qualificados e capazes de manipular ferramentas sofisticadas. O setor produtivo reconstrói suas hierarquias à medida que novos conhecimentos e instrumentos de trabalho vão predominando no espaço fabril.

Essa vertente sofreu diversos questionamentos da parte da Sociologia do Trabalho marxista. Essa corrente alega que as hierarquias profissionais surgem e se consolidam muitas vezes independentemente das inovações tecnológicas. Em seus estudos sobre as tranformações do sistema fabril na Inglaterra, o sociólogo Stephen Marglin (2001) aponta que em diversos setores, a transformação do produtor independente em trabalhador assalariado ocorreu antes mesmo da implantação de máquinas sofisticadas.

Isso significa que a perda de autonomia tanto dos operários como dos técnicos no processo produtivo não foi o resultado de uma maior complexidade das ferramentas produtivas, como defendem certos ramos da economia industrial, mas sim decorrência de uma necessidade de controle que torne regulares e previsíveis as formas de trabalho.

O segredo do sucesso da fábrica, o motivo de sua adoção, é que ela tirava dos operários e transferia aos capitalistas o controle do 
processo de produção. Disciplina e fiscalização podiam reduzir os custos, na falta de uma tecnologia superior. (Marglin, 2001, p. 58).

As formas organizacionais de gestão do trabalho fabril ocupam uma posição central na definição de competências e na abrangência da interferência tanto de operários como de técnicos e cientistas. Desde o início do capitalismo é possível detectar a presença marcante do extratécnico direcionando as decisões e os princípios da competência técnica, em outras palavras, uma colonização do gesto técnico.

Os sociólogos marxistas detectam que uma tendência de autonomização dos técnicos, propalada apressadamente por alguns autores, como Mallet, não se sustenta. Para Gorz (2001), nos anos 70 ficou patente que a condição privilegiada dos técnicos e pesquisadores de grandes laboratórios e firmas de alta tecnologia passou a sofrer diversos reveses, à medida que eram submetidos a treinamentos específicos e novas formas de controle, por meio de métodos de avaliação de resultados.

Apesar desses profissionais não conseguirem se identificar com a classe operária tradicional em função de diversos aspectos culturais e políticos, sua autonomia e capacidade de intervenção no sistema produtivo são extremamente limitadas, uma vez que

[...] os trabalhadores da ciência e da técnica têm, no interior de sua função técnico-científica, a função de reproduzir as condições e as formas de dominação do capital sobre o trabalho. (Gorz, 2001, p. 217).

Nos anos 80, o tema da reestruturação produtiva e a consolidação das técnicas japonesas de gerenciamento (toyotismo) trouxeram outros elementos para esse debate. A discussão sobre o pós-fordismo e a precarização do trabalho trouxe novamente a questão da delimitação entre classe operária e setores qualificados (Antunes, 1995). 
No entanto o operário polivalente, detentor de alta qualificação e capacidade de intervenção no espaço produtivo, sofre uma intensificação de suas responsabilidades e atribuições, além de sustentar o incômodo de participar do processo de acumulação capitalista. Assim como o operário tradicional, ele precisa justificar seu trabalho a partir da viabilidade da acumulação e da realização da mais-valia, independentemente do conteúdo de sua qualificação técnica.

Para a literatura que discute os efeitos da reestruturação produtiva sobre o trabalho de técnicos e cientistas, a atividade destes deve ser percebida a partir do seu posicionamento nas relações de produção, não importando tanto o conteúdo específico dessa atividade. Ou seja, a tendência da expansão capitalista é diminuir os custos e a importância do trabalho, independentemente da intervenção específica que sua habilidade técnica possa propiciar.

Os mecanismos e estratégias levados a cabo pelas técnicas de gerenciamento produtivo igualam técnicos e pesquisadores aos operários tradicionais, a despeito da existência de um sem número de funções diversificadas e remunerações específicas. A identidade funcional daqueles tende a perder consistência mesmo em setores estrategicamente relevantes, como informática.

Segundo Lojkine (1995), há na economia moderna fundada na informatização um cruzamento complexo entre qualificações e atribuições distintas, em que um grande contingente de técnicos e pesquisadores precisa se submeter a parâmetros coesos e impermeáveis.

[...] uma elite de quadros dirigentes se opõe cada vez mais a um pluralidade de frações sociais dominadas e frequentemente exploradas, mesmo se suas funções de criação e de organização erguem uma barreira eficaz contra toda assimiliação simplista ao salariato e ao mundo do "trabalho". (Lojkine, 1995, p. 272). 
O problema dessa abordagem é que ela descontextualiza a atividade técnico-científica de seus espaços concretos, tornando os técnicos ora como servidores do capital, ora como setores de classe média. A atividade técnica é subsumida a seus aspectos profissionais e econômicos, e esvaziada de conteúdos específicos.

A partir dos anos 90, a perspectiva da inovação tecnológica tornou-se um desafio adicional à Sociologia do Trabalho. Um dos temas em tela passa a ser como o movimento sindical é capaz de dialogar com as iniciativas de inovação tecnológica e patenteamento de produtos pelas empresas.

No caso brasileiro, grande parte do movimento sindical desfruta de potencial limitado para debater qualificadamente os rumos do processo inovativo. Segundo a análise de Cardoso (1999, p. 167),

os sindicatos (com raras exceções), mantidos na porta das fábricas, não criam expertise para negociar em pé de igualdade com as empresas a renovação dos processos produtivos, com o que elas puderam fazê-lo de forma quase sempre unilateral.

No geral, os sindicatos mantêm uma posição reativa e pouco consistente no estabelecimento de uma agenda tecnológica. Faz-se necessário aprofundar mecanismos de representação nas empresas e cursos de qualificação técnica, sem o que a intervenção dos trabalhadores continua em um patamar acessório e pouco efetivo.

De acordo com Cotanda (2007), as empresas continuam dispondo de uma série de prerrogativas que as tornam impermeáveis às solicitações do meio sindical, tais como o estabelecimento de cláusulas genéricas sobre aprendizado tecnológico, não transferência de conhecimento técnico atualizado, e capacidade superior de estabelecer sinergias com laboratórios e centros de pesquisa.

Apesar da complexificação constante do setor produtivo, um sem número de agentes e lideranças sindicais manifestam 
incapacidade de acompanhar o patamar das empresas nas práticas de inovação. Categorias de trabalhadores mais qualificados como jornalistas e aeroviários apontam esse mesmo problema, o que leva a crer que mesmo indivíduos mais dotados de conhecimento técnico são impossibilitados de interferirem nos rumos da inovação.

A Sociologia do Trabalho e as análises do meio sindical apontam que se mantém uma situação paradoxal em relação ao posicionamento dos técnicos no capitalismo contemporâneo. Ao mesmo tempo que são agentes fundamentais para dar coerência e funcionamento aos sistemas técnicos mais abrangentes e inclusivos, estão incapacitados de aprimorar suas formas de intervenção e decisão.

Essa discussão, apesar de remontar aos primórdios das análises sociológicas sobre a esfera de trabalho capitalista, está presente também em outras correntes de pensamento, como a problemática da inovação de acordo com a tradição do pensamento econômico, como veremos a seguir.

\section{A rotinização da técnica na Economia da Inovação}

O tema da inovação traz diversos aspectos para a problemática da autonomia dos técnicos no capitalismo que são diferentes das questões levantadas pela Sociologia do Trabalho. Os problemas centrais deixam de ser as fronteiras da classe operária com os técnicos e pesquisadores, ou os impactos da reestruturação produtiva sobre as formas de acumulação de capital.

A agenda schumpeteriana da Economia da Inovação redimensiona as preocupações da atividade técnica. O comportamento de técnicos e pesquisadores nas universidades, firmas e nos conselhos de política científica são aspectos centrais para o desenvolvimento de sinergias e para a formulação de incentivos 
eficientes. O relacionamento entre expertise e interesses econômicos e sociais representa uma questão fundamental para se entender o problema da autonomia técnica em sociedades de alta tecnologia.

O planejamento das práticas tecnológicas, o intercâmbio de informações e a organização da comunidade de cientistas e pesquisadores estimulam outras modalidades de análises sobre a autonomia de técnicos e cientistas, vistos agora não apenas como força de trabalho mas enquanto portadores de conhecimento estratégico para o desenvolvimento econômico (Lemos, 2000).

Essa problemática é composta de um rol de questões políticas e administrativas voltadas para a gestão da inovação tecnológica. Técnicos e cientistas precisam dar respostas a um sem número de imposições oriundas das Políticas de Ciência e Tecnologia que adquirem complexidade e abrangência crescente.

Os instrumentos de gestão tecnológica transformam-se em aspectos estratégicos nos países avançados, que criam comissões e agência públicas para a formulação de políticas setorizadas em diferentes áreas científicas. Cientistas, decision makers e empresários têm desenvolvido critérios de legitimação da atividade inovativa de forma a estabelecer diretrizes para os investimentos científicos e econômicos. Segundo muitos autores, isso tem levado a uma crescente burocratização dos modelos de decisão sobre as políticas científicas e tecnológicas (Dagnino, 2007).

$\mathrm{O}$ uso recorrente de metodologias gerenciais, como planejamento estratégico e idenificação de prioridades, têm significado uma intervenção crescente sobre a agenda dos especialistas em diversos contextos (Dagnino, 2007).

Segundo Zackiewicz, passa a se consolidar nas economias centrais durante as últimas décadas um controle externo da ciência e da tecnologia, implicando fórmulas mais precisas de avaliação de resultados e simulação de sinergias entre áreas diversas. 
As práticas da escola de forecasting foram incentivadas pelos esforços dos governos em legislar sobre a ciência - especialmente sobre a custosa big science - e produzir accountability. Embora ainda sob perspectivas bastante diferentes, a partir do pós-guerra tanto a avaliação (externa) das atividades científicas quanto a previsão de seus avanços passaram a ser cada vez mais tratados por métodos com fortes influências da teoria econômica. A ciência, cada vez mais, precisava provar quantitativamente sua utilidade. (Zackiewicz, 2003, p. 196-197).

Com isso, a capacidade de correr riscos ou realizar experimentações livres fica condicionada a certos aspectos e operações; não fazem mais parte das atividades cotidianas de uma empresa ou laboratório. Todo um aparato institucional, financeiro e econômico é construído em torno da inovação (Sanidas, 2003).

Desde as formulações de J. Schumpeter (1982) no início do século XX, a problemática da inovação esteve claramente articulada com a teoria da empresa. O empresário moderno representa a síntese entre a iniciativa organizacional e a pujança de novos conhecimentos e ferramentas. No pensamento neoschumpeteriano, o desenvolvimento empresarial se articula à internalização de práticas de pesquisa e desenvolvimento e à cotidianização da renovação de processos na atividade econômica.

Em Schumpeter, essa problemática da autonomia e da burocratização das atividades tecnológicas é controversa. Em determinadas passagens de sua obra Capitalismo, Socialismo e Democracia, ele aponta que, conforme o avanço científico ocorresse mais fortemente, as inovações tecnológicas tornar-seiam mais rotineiras e previsíveis, não havendo mais espaço para experimentações e incertezas. Em sua palavras,

essa função social [do empresário] já perde hoje importância e provavelmente perderá cada vez mais no futuro, mesmo se o processo econômico, do qual o empresário foi a mola-mestra, continuar sem desfalecimento. Pois, de um lado, é muito mais fácil 
agora que no passado realizar coisas estranhas ao nosso rotineiro campo de atividades. A própria inovação está hoje reduzida à rotina. O progresso tecnológico se transforma cada vez mais em atividades de grupos de especialistas, que fornecem o que lhes recomenda e fazem o produto operar de uma maneira previsível... (Schumpeter, 1961, 167).

Apesar de Schumpeter conceber a atividade de inovação como um aspecto definidor da economia em termos evolutivos e dinâmicos, ele faz um prognóstico pessimista em relação ao acoplamento instaurado entre os diferentes domínios da empresa e a atitude de cientistas e tecnólogos. À medida que os processos inovativos se institucionalizam, estabelecendo metas e funções definidas entre empresários, firmas e especialistas, a incerteza se molda ao planejamento.

A rotinização das atividades tecnológicas tenderia a conduzir o capitalismo a uma planificação próxima do sistema socialista. Alguns autores apontam que Schumpeter teria errado em sua previsão, uma vez que as economias socialistas faliram porque as inovações lá produzidas se rotinizaram (ver Nelson, 2006).

A nosso ver, o problema da rotinização da inovação no capitalismo avançado não pode ser prontamente descartado, uma vez que aponta para questões relevantes frente ao posicionamento dos técnicos no mundo contemporâneo que precisam ser melhor debatidos. Até o século XIX, o avanço industrial em diversos ramos empresariais era devido principalmente à atuação de operários e inventores. Segundo o economista Christopher Freeman (1975, p. 28-29), nos primeiros séculos da industrialização dos países avançados,

o progresso técnico foi rápido, mas as técnicas eram tais que a experiência e o engenho mecânico motivaram muitas melhorias como resultado da experiência direta e da experimentação em escala reduzida. A maioria das patentes daquele período se deve a "mecânicos" ou "maquinistas" que realizavam seu próprio trabalho 
de "desenvolvimento" paralelamente à produção ou de forma privada.

Segundo esse autor, é possível perceber que, em alguns ramos específicos, as empresas podem dispor de departamentos técnicos ou de engenharia que contribuem muito para o aperfeiçoamento tecnológico, por meio de princípios de experimentação e conhecimento tácito. Mas à medida que o setor de Pesquisa e Desenvolvimento (P\&D) passa a compor a estrutura interna das empresas, todo um conjunto de práticas se modifica. Técnicos e cientistas passam a articular suas atividades com princípios organizacionais mais precisos e controlados, não mais respeitando incondicionalmente seus hábitos e rituais. Na maior parte do tempo, técnicos e engenheiros precisam se dedicar a resolver problemas relacionados ao ritmo e ao processo normal da produção, deixando para segundo plano ou de forma controlada e subsidiária a prática de experimentação e testes (Freeman, 1975, p. 34-35).

À medida que novos paradigmas tecnológicos se configuram, a competitividade das empresas advém do fato que as corporações secretam as habilidades e memórias indispensáveis para se adaptarem aos constrangimentos ambientais. Com isso, técnicos e engenheiros não são os agentes preferenciais para a resolução de problemas situados na interface entre a empresa e o mercado. Essa conjugação complexa exige das firmas a capacidade de previsão e busca de oportunidades contextuais para um bom desempenho econômico (Dosi, 1988).

O tema das aptidões tecnológicas representa um dos aspectoschave na implementação de políticas industriais. Diversos autores discutem a importância do desenvolvimento de aptidões para o aprimoramento do potencial das economias emergentes.

Essas aptidões dependem fundamentalmente do investimento em conhecimento técnico especializado e da formação de pessoal 
com habilidades e qualificação atualizados. Mas o desenvolvimento das aptidões enfrenta atualmente um impasse. No capitalismo contemporâneo há uma diferenciação progressiva entre políticas tecnológicas e inovativas. De um lado, o estabelecimento de políticas tecnológicas nos países avançados pauta-se pelo incremento de habilidades e aptidões, calcadas em investimentos de política industrial e centífica. Por outro lado, o estabelecimento de metas de inovação se inscreve em um processo de viabilização de patentes e de propriedade intelectual.

Essa diferenciação entre políticas tecnológicas e de inovação é perceptível em diferentes contextos produtivos. Segundo Dodgson (2005), determinadas empresas podem ter um bom desempenho inovativo em termos de aquisição de patentes, mas a falta de criatividade tecnológica impede o alcance de metas de longo prazo. As imposições do sistema de P\&D muitas vezes inviabilizam a construção de práticas inovativas consistentes e duradouras, e a liderança tecnológica se compromete. Ele cita o caso da Samsung como emblemático dessa tensão.

Atualmente, a Samsung emprega 14.500 pesquisadores, possui mais de vinte laboratórios de pesquisa, registra acima de 750 patentes por ano nos Estados Unidos e tem atraído parcerias de cooperação em P\&D com muitas das melhores empresas de alta tecnologia do mundo. No entanto, continua sendo frágil a capacidade de muitas empresas do Leste Asiático, como a Samsung, de lidar com a criatividade tecnológica, assim como com a concorrência internacional, especialmente em relação à superburocratização (e, portanto, às restrições à criatividade) da atividade de $\mathrm{P} \& \mathrm{D}$. (Dodgson, 2005, p 332).

As empresas altamente competitivas enfrentam o dilema de investir em políticas avançadas de inovação que, contudo, não representam incremento em termos de aptidões tecnológicas. É possível para determinados ramos industriais adquirir grande número de patentes sem ampliar o próprio desempenho tecnológico. 
Para Rosenberg (2006), um dos expoentes da teoria evolucionista das técnicas, a questão do aprendizado pelo uso é essencial para se entender a inovação tecnológica em setores de alta complexidade. Ele se diferencia fortemente do aprendizado pela prática, uma vez que este último está intrinsicamente relacionado a estratégias econômicas e ao processo produtivo. $\mathrm{O}$ aperfeiçoamento tecnológico pelo uso pressupõe um acompanhamento dinâmico e complexo de um sem número de componentes e propriedades que ocorrem muito para além de sua significação econômica, pois

[...] numa economia com novas tecnologias complexas, existem aspectos essenciais da aprendizagem que são função, não da experiência envolvida na produção do produto, mas de sua utilização pelo usuário final... Assim, o aprendizado pelo uso refere-se a um local de aprendizagem muito diferente daquele da aprendizagem pela prática. Há muitas razões por que isso deve ser assim. Talvez, em termos mais gerais, as características de desempenho de um bem de capital durável frequentemente não possam ser entendidas antes que se tenha tido uma prolongada experiência com ele. (Rosenberg, 2006, p. 188-189, grifo original).

Em outras palavras, em sistemas tecnológicos de grandes proporções, como no caso do setor de aviação, não há como prever acuradamente a resistência dos materiais, o desempenho de componentes e a acoplação de engrenagens em novas cadeias de transmissão. O rendimento técnico tem que ser buscado continuamente dentro de uma margem de indeterminação cambiante, o que depende de uma valorização da experimentação técnica.

Segundo Rosenberg (2006, p. 1889), a tecnologia contemporânea solicita um tratamento cada vez mais específico e empírico, uma vez que

boa parte do conhecimento técnico necessário nas sociedades de alta tecnologia tende a ser extremamente especializado ou específico com respeito à natureza do processo e às máquinas envolvidas. Esse conhecimento não apenas não pode ser predito com precisão a partir dos princípios ou da metodologia da ciência, mas... ele tampouco 
pode sê-lo com base na experiência com tecnologias análogas ou correlatas. (Rosenberg, 2006, p. 189).

A prática indutiva dos engenheiros e outros profissionais diretamente ligados à prática tecnológica muitas vezes não repercute fortemente nos contornos da inovação industrial. Esse diagnóstico aponta para uma tendência de recrudescimento das rotinas administrativas das empresas, muitas vezes impermeáveis às demandas da própria capacidade tecnológica instalada.

$\mathrm{Na}$ construção do chamado capitalismo informacional, Castells (1999) aponta que a inventividade dos pioneiros e líderes de empreendimentos tecnológicos foi um fator de vital importância para a cristalização de um conjunto de instituições e redes de empresas. Não apenas as rotinas administrativas fundaram os pilares do capitalismo informacional moderno, mas a experimentação constante e aberta fez com que áreas de conhecimento diferentes pudessem convergir nesse idioma, estabelecendo um diálogo constante de técnicos e empresários.

A superburocratização que atinge as atividades de $\mathrm{P} \& \mathrm{D}$ representa, em diversos ramos da Economia da Inovação, um desafio a ser enfrentado por empresas, laboratórios e Estado. Apesar de todo o incentivo estratégico e operacional para o desenvolvimento tecnológico, o conhecimento técnico e científico continua sendo fundamental, em sua especificidade e contingência.

É possível perceber a existência de uma tensão interna nessa área de pensamento, um sinal de que a prática inovativa suscita diversos questionamentos, gerenciais, econômicos e culturais.

\section{Sociologia da Ciência e a autonomização dos técnicos e cientistas}

Para Merton (1970), o tema da autonomia da comunidade científica diante de outros agentes é central. Nos anos 40, ele 
iniciou toda uma tradição de pensamento que conferia importância essencial à autonomização dos cientistas perante a esfera da política no mundo contemporâneo e a formação de um "ethos" específico. Esse tema se desdobrou de diversas formas na Sociologia da Ciência. Diferentes correntes têm buscado discutir como técnicos e cientistas reconstróem suas atividades após o recente advento da Big Science e das modernas políticas de inovação tecnológica (Kreimer, 1999).

Autores ligados à área da Sociologia da Ciência também detectam a importância de se discutir a crise do gesto técnico no capitalismo contemporâneo. Uma das principais questões que esses autores vêm discutindo é a relação entre empreendedorismo e a conduta de cientistas e técnicos em laboratórios e centros de pesquisa.

Lamy e Shinn (2006) apontam que há uma tendência em curso de diversas correntes de se enxergar uma indiferenciação entre prática científica e tecnológica de atividades mercantis. O projeto mertoniano de conceber uma determinada autonomia da prática científica vem sendo substituído por uma lógica em que o empreendedorismo moderno submete à prática mercadológica tanto os técnicos como os pesquisadores. Esses agentes precisam incorporar racionalidades ou perspectivas econômicas de modo a se adaptarem ao novo modelo de inovação e produção de conhecimento. Segundo os autores,

[...] os antidiferencionalistas [...] têm em comum a posição de rejeitar a idéia de autonomia da ciência e seus praticantes, e de criticar a diferenciação entre cientistas e empreendedores. (Lamy; Shinn, 2006, p. 24).

Há, portanto, uma tendência segundo a qual os pesquisadores precisam tornar-se empreendedores. Dentro da nova Economia do Conhecimento, não é mais possível aos técnicos e inovadores atuarem de acordo com outros parâmetros que não os produtivos; então, eles precisam comungar dos mesmos propósitos e princípios 
administrativos que os novos empresários e empreendedores da área de gestão do conhecimento e difusão de informações.

De acordo com essa corrente de pensamento, a inovação depende menos de inventividade técnica e mais da criação de redes de circulação de informação e conhecimento. A problemática da inovação torna-se menos tecnológica e mais organizacional, adquire um sentido econômico (distributivo) e social (de coesão) que transcende os ditames operacionais e funcionais da técnica (Lemos, 2000, p. 170).

Os arranjos organizacionais e os formatos interativos entre agentes científicos e econômicos tomam o centro do debate inovativo e das práticas tecnológicas. O conteúdo específico de uma determinada tecnologia não é tão relevante quanto o arcabouço gerencial e o sistema cooperativo criado em seu entorno.

Em outros termos, os agentes tecnológicos precisam incorporar uma dimensão gerencial e administrativa que viabilize os arranjos empresariais e, para isso, uma certa padronização de comportamentos $\mathrm{e} o$ atendimento às demandas produtivas é essencial, pois técnicos e cientistas compartilham de um mesmo ethos.

Lamy e Shinn (2006) discutem como os técnicos e cientistas franceses têm se comportado diante da mercantilização da pesquisa, possibilitada pela nova Lei de Inovação Tecnológica que se implantou naquele país. Eles apontam que há uma tendência de que os cientistas empreendedores articulem práticas científicas e mercantis de modo a preservarem as especificidades das duas áreas. Segundo os autores, ocorre uma alternância de comportamentos acadêmicos e empresariais por parte dos pesquisadores empreendedores, de modo que sequencialmente, e de forma contextualizada, os pesquisadores e técnicos adaptam seus interesses ora em termos científicos, ora em termos econômicos. Essa discussão é interessante, uma vez que coloca em questão a tese antidiferencialista, e, ao mesmo tempo, 
salienta a contingência do comportamento cienífico. Muitas vezes os cientistas empreendedores

alternam um regime de empreendimento e um regime acadêmico. A constatação da existência desse modo de coordenação sequencial confirma a possibilidade de uma preservação não patológica de diferenças entre ciência e mercado. (Lamy; Shinn, 2006, p. 49).

Segundo os autores, não é tão simples detectar que técnicos e pesquisadores incorporam a lógica mercantil. Determinadas áreas do conhecimento se abrem a investimentos empresariais, de modo que novas práticas e interesses se entrecruzam tomando a forma de medidas pontuais e de curto prazo que, no entanto, não caracterizam adesão incondicional às regras de mercado.

Outro tema desponta na moderna Sociologia da Ciência: a relação entre os pesquisadores e cientistas e a administração científica. Ao analisar a constituição de redes de atores ligados à pesquisa de biotecnologia no Brasil, Trigueiro (2002) avalia que técnicos e empreendedores submetem suas agendas de trabalho a aspectos ligados à gestão de projetos e ao aperfeiçoamento organizacional. Aparece claramente um conflito entre a aptidão tecnológica dos pesquisadores e técnicos e a capacidade de gestão e obrigações corporativas.

A superburocratização das atividades de prospecção e estabelecimento de contratos de prestação de serviçoes e convênios torna a prática de técnicos e cientistas um emaranhado de tarefas sobrepostas que não permite buscar ligações fora dos parâmetros acordados contratualmente.

De uma atividade humana aberta e flexível, a prática tecnológica precisa se adequar sistemicamente a uma agenda social antecipatória e imperativa, que submete os agentes tecnológicos a cronogramas e metas determinadas (Stiegler, 1998). 
Opensamento deBourdieu(1983) deu umnovo direcionamento a essa discussão. Ele se utiliza da noção de campo para mostrar que as instituições científicas possuem em seu interior um conflito ora velado ora explícito entre seus diferentes membros. Pesquisadores e administradores, jovens e seniores, lançam mão de seus diferentes recursos materiais e simbólicos com vistas a procurarem impor seus padrões de legitimidade científica.

Analisando o caso do Instituto Nacional de Pesquisa Agrícola francês (INRA) enquanto campo marcado por disputas para se definir a competência técnica e científica, Bourdieu (2004) afirma que o incremento da lógica administrativa e gerencial do Instituto tem prejudicado o exercício do diálogo dos pesquisadores entre si. Faz-se necessário, segundo ele, uma prática de desierarquização de funções com o intuito de viabilizar a compatibilização do conhecimento científico produzido pelos pesquisadores com as demandas reconhecidas pela instituição.

Um dos grandes desafios, segundo Bourdieu (2004), é como lidar com a administração científica. $\mathrm{O}$ crescimento da importância dos gestores e administradores científicos tem colocado em posições contrárias dois tipos de capital científico: o capital científico puro, detido pelos especialistas em suas diversas qualificações, e o capital científico institucionalizado, controlado por instâncias de direção dos centros de pesquisa. Para Bourdieu (2004, p. 62-63),

Se penso que medidas administrativas visando melhorar a avaliação da pesquisa e colocar em prática um sistema de sanções [...] próprias para favorecer as melhores pesquisas e os melhores pesquisadores seriam as mais ineficazes e teriam como efeito, mais provavelmente, favorecer ou reforçar as disfunções que supostamente deveriam ser reduzidas, é porque tenho sérias dúvidas seriamente fundadas sobre a capacidade das instâncias administrativas para produzirem avaliações realmente objetivas e inspiradas.

A autonomia científica representa um desafio a ser enfrentado à medida que gestores e administradores científicos acumulam um 
capital de prestígio no interior das instituições de pesquisa. Esses agentes, segundo Bourdieu, estão imunes a avaliações de outros, e são responsáveis pelo engessamento e padronização das atividades de técnicos e pesquisadores, que não são detentores de um mesmo capital de prestígio no plano institucional.

Técnicos e pesquisadores que buscam empreender suas atividades alheios aos padrões de realização da gestão estratégica de institutos de pesquisa e empresas representam entraves às metas de desenvolvimento dessas instituições. Para essas correntes, as técnicas organizacionais e de controle da atividade científica adquirem legitimidade ao sintonizarem seus pesquisadores aos programas institucionais de desenvolvimento.

Essa discussão tem sofrido uma série de resistências da parte da sociologia construtivista e contextual da ciência e das técnicas. Segundo essa linha de pensamento, que desde os anos 80 vem redefinindo a discussão sobre autonomia científica, a relação entre técnicos e pesquisadores com outros campos é muito mais complexa.

Para Knorr-Cetina (2005), não faz sentido discutir a autonomia dos agentes técnicos e científicos uma vez que estes estão incorporados a campos transcientíficos que são compostos por lógicas as mais diversas. Existem relações de recursos, segundo os termos de Knorr-Cetina, que exigem um imbricamento contextual em que alunos e orientadores, técnicos e gerentes estabelecem acordos ora de conflito, ora de cooperação, em que a lógica do campo científico precisa estabelecer analogias e aproximações com outras formas de pensamento.

A dinâmica da produção de conhecimento transcende a noção de campo científico ou comunidade científica, uma vez que se faz necessário lidar com perspectivas econômicas, políticas e linguísticas diversas. Então, a prática científica não carece de autonomia, mas sim está envolvida em uma rede múltipla de causalidades, 
campos transcientíficos variáveis, que "[...] nos remetem a redes de relações simbólicas que em princípio transcendem os limites de uma comunidade científica ou campo científico em suas amplas definições" (Knorr-Cetina, 2005, p. 204).

A Sociologia das Técnicas desenvolvida principalmente por Latour e Callon, entende de forma semelhante a relação entre pesquisa e administração científica. Segundo Latour (2000), os técnicos e cientistas sofrem ingerências constantes de setores extra-científicos a partir de um sem número de contextos e situações específicas que se desenrolam aleatoriamente dentro e fora dos laboratórios.

Em sua obra Ciência em ação, Latour (2000) descreve um sem número de situações nas quais técnicos e engenheiros são envolvidos em redes de poder que constrangem e condicionam a implementação de projetos e a viabilização de sistemas técnicos.

Esses constrangimentos, no entanto, não se inscrevem dentro das práticas do campo científico; eles transcendem os interesses dos agentes do campo. Para Latour, aquilo que ocorre fora dos laboratórios - e, portanto, exógenamente à racionalidade científica-, é tão fundamental quanto esta para explicar a autonomia científica.

Nem o mercado, nem as instituições de pesquisa são capazes de estabelecer um padrão de atividade técnica sem que ele derive de arranjos e articulações as mais diversas, envolvendo células, sindicatos, consumidores e órgãos públicos.

Essa rede de agentes inviabiliza a construção de ferramentas antecipatórias confiáveis, de modo que toda criação técnica é obra de uma conjunção de fatores e a autonomia técnica significa o potencial de recrutar e convencer agentes diferenciados a compartilharem os mesmos pressupostos.

Dentro dessa linha de argumentação, limitações e sanções não são impostas somente pelo campo científico, mas por um conjunto desordenado de procedimentos e interesses. 
É possível perceber que duas linhas de pensamento sobressaem na moderna Sociologia da Ciência sobre esse tema: a perspectiva do campo científico de Bourdieu e a abordagem do ator-rede de Latour. Para essa segunda, fica um tanto nebulosa a percepção dos conflitos no interior da atividade técnico-científica, uma vez que diferentes racionalidades se interpõem no contexto de pesquisa.

\section{Filosofia das Técnicas e a crise do gesto}

No mundo contemporâneo aponta-se uma crise do gesto técnico enquanto intermediário entre os homens e o meio social, no qual se tende a reduzir a inovação a certas prática formais. De uma atividade humana aberta e flexível, a inovação tecnológica precisa se adequar sistemicamente a uma agenda social antecipatória e imperativa, que submete os agentes tecnológicos a cronogramas e metas determinadas (Stiegler, 1998).

Como foi visto acima, o gesto técnico precisa cada vez mais se adaptar aos não técnicos. Há uma tendência crescente de firmas e outras instituições estabalecerem padrões de gestão mais aprimorados que guiem e antecipem as atividades dos técnicos e engenheiros, o que provoca tensões diferenciadas em termos de expectativas tecnológicas e práticas administrativas.

A questão da experimentação técnica é um tema especialmente importante na Filosofia e Sociologia das Técnicas. Diversos autores têm discutido a importância da autonomia e atuação dos técnicos para o avanço e coerência dos sistemas tecnológicos, o que possui diversas implicações para se compreender a lógica da inovação.

A Filosofia das Técnicas adentrou fortemente nesse debate nos anos 50, tendo ainda grandes repercussões no pensamento contemporâneo. A teoria da concretização formulada pelo filósofo Gilbert Simondon (1969) contribui fortemente para essa discussão. 
Em seus estágios iniciais, os objetos são considerados abstratos ou artificiais por não possuírem uma coesão interna e os homens precisarem constantemente intervir para garantir seu funcionamento. Um exemplo dessa fase precária dos objetos técnicos corresponde a sua configuração como ferramentas ou utensílios, totalmente dependentes da manipulação humana. À medida que os objetos evoluem, a necessidade de participação humana diminui:

Com a evolução, esse objeto perde seu caráter artificial: a artificialidade essencial de um objeto ocorre porque o homem precisa interferir para manter o objeto existindo, protegendo-o contra o mundo natural e dando a ele uma forma separada de existência. (Simondon, 1969, p. 46-47).

O objeto técnico concreto resulta em um corpo plenamente ajustado, guardando várias semelhanças para com os seres vivos. Ele não precisa mais de um suporte exterior que possibilite seu rendimento. Ao contrário, ele pode existir tanto isoladamente quanto em associação com outros objetos, pois sua constituição integrada e sinérgica o faz prescindir de um suporte exterior.

Esta formulação adquire importância na proporção em que redefine a conceituação dos objetos técnicos, em que sua importância reside menos em uma funcionalidade restrita e mais no potencial criativo de compatibilidades internas. O motor de aviões é exemplo de objeto técnico mais concreto do que seu antecessor (o motor de carros), uma vez que não necessita de refrigeração por água, sendo este um recurso que implica uma regulação externa sobre o objeto. Segundo argumento do próprio Simondon (1969, p. 25),

[...] em um motor de combustão interna, a refrigeração pode ser realizada por um subconjunto inteiramente autônomo; se esse subconjunto pára de funcionar, o motor se deteriora; se, ao contrário, a refrigeração é realizada por um efeito solidário do funcionamento do conjunto, o funcionamento implica a refrigeração...

A necessidade de refrigeração por água representa a falta de articulação entre as engrenagens internas do motor e demanda 
a intervenção pontual de um elemento externo, o carburador, com uma função única e inessencial. No objeto concreto, esse apêndice regulador desaparece e ele adquire uma feição mais sinérgica e recorrente.

O conceito de concretização altera os parâmetros de avaliação da esfera técnica, privilegiando mais diretamente a constituição compatibilizada e sinérgica dos objetos e seus dispositivos. Dessa forma, os objetos não são avaliados segundo uma perspectiva utilitária e antropocêntrica, mas de acordo com parâmetros mais propriamente técnicos.

O motor de aviões apresenta uma articulação interna mais sofisticada, com um peso menor de acessórios inessenciais e um ganho de coerência e autoacoplamento. E de onde vem essa maior sinergia e autossuficiência do motor dos aviões, que tiveram um efeito posterior decisivo no desenvolvimento do automóvel? Exatamente da experimentação contínua e do aperfeiçoamento pelo uso. Não foi o estabelecimento de metas exógenas à atividade tecnológica que permitiram um avanço nas formas de refrigeração dos motores e o posicionamento das asas, e nem a busca de rendimentos financeiros mais rápidos.

O investimento racionalizado em formulação de políticas e incentivos governamentais e financeiros à inovação tecnológica corre o risco de não atender a especificidades e propriedades que somente a atuação direta e contextualizada dos inovadores pode alcançar. É isso que o autor entende por predomínio das condições técnicas, o reconhecimento de que a articulação de objetos e sistemas tecnológicos atende a demandas específicas e não transferíveis.

Comparando a trajetória de desenvolvimento dos motores de aviões e automóveis,

[...] não é surpreendente que o scooter seja fruto do trabalho de um engenheiro especialista em aviação; enquanto o automóvel pode se 
permitir conservar resíduos de abstração (refrigeração a água...), a aviação é obrigada a produzir objetos técnicos mais concretos, para aumentar a segurança e diminuir os pontos obscuros [...]. (Simondon, 1969, p. 26).

$\mathrm{O}$ autor defende que o funcionamento dos objetos não se restringe a uma postura adaptativa ou defensiva perante a imposições sistêmicas, mas lança operadores, técnicos e objetos a um diálogo em aberto diante das possibilidades de articulação entre gesto humano, dispositivos e pensamento. Em seu importante texto sobre a relação entre individuação e invenção, Simondon (1989, p. 263) proclama a necessidade de liberdade dos indivíduos dotados de engenhosidade técnica:

O técnico só pode agir livremente, pois a normatividade técnica é intrínseca em relação ao gesto que a constitui; ela não é exterior ou anterior à ação..a normatividade técnica é intrínseca e absoluta $[\ldots]$.

As normas da operação técnica são acessíveis aos indivíduos sem que ele precise se submeter a uma normatividade social. É a partir da operação técnica indutiva e experimental que os conjuntos técnicos ganham dinamismo e coerência, e avançam para configurações mais ajustadas.

A inventividade técnica é, portanto, relativamente independente tanto da metodologia científica como da produção econômica. A concepção antropomórfica que relaciona o desenvolvimento técnico com os interesses humanos e as metas sociais não consegue levar em conta a tendência a um aprimoramento do funcionamento sinérgico dos dispositivos técnicos. Eles se estabilizam a partir de um aumento da convergência de tendências na progressão de seu funcionamento.

Ao responderem a ingerências impostas por metas corporativas, os técnicos criam um conflito velado entre as práticas 
de gestão tecnológica e as vicissitudes cotidianas da experimentação técnica, como é patente na produção de aeronaves.

O filósofo marxista Andrew Feenberg (1991) desenvolve uma abordagem sobre a tecnologia moderna que permite reorientar a percepção da atividade inovativa e sua inserção no mundo. Sua teoria crítica da tecnologia defende que o pensamento crítico da Escola de Frankfurt foi incapaz de enxergar a concretude das práticas técnicas do capitalismo, permanecendo num reino abstrato da tecnologia enquanto manifestação ideológica. O desenvolvimento técnico é fortemente social, e os objetos e sistemas desenvolvidos na sociedade capitalista trazem a marca dos princípios da concorrência e do individualismo burguês. Isso produz uma descontextualização da tecnologia diante de seu substrato material e ambiental, tornando o projeto tecnológico hegemônico do capitalismo uma construção inviável e abstrata.

Contrariamente à visão heróica do empreendedor schumpeteriano, articulador de novas combinações avançadas e integrativas, Feenberg enxerga o empresário capitalista como um descontextualizador da técnica em face das condições sociais, agente desvinculado e desinteressado dos processos sociais dominantes em nome de uma concentração arbitrária de conhecimento e energia.

O projeto tecnológico é diferente das tecnologias per se, e é contra ele que se voltam as principais críticas dos defensores da reforma tecnológica, uma tendência de movimento que pretende articular a inovação às demandas de setores não hegemônicos (Dagnino, 2008).

Para se entender o rumo das inovações técnicas, os setores mais avançados como aviação, informática e energia elétrica mostram que é necessário investigar o sentido da prática dos engenheiros e seus materiais, o que inclui também elementos físicos e inanimados e um grau de indeterminação constitutivo da própria atividade técnica. 


\section{Conclusão}

As áreas de conhecimento discutidas (Sociologia do Trabalho, Economia da Inovação, Sociologia da Ciência e Filosofia das Técnicas) partem de premissas distintas e abordam aspectos específicos desse tema, o que auxilia sobremaneira na percepção dos diversos impasses e possibilidades de reflexão.

Em grande medida, a Sociologia do Trabalho parte do princípio de que técnicos e cientistas, embora sejam agentes importantes do capitalismo contemporâneo, sentem as consequências do enquadramento restritivo e instrumental de suas atividades. Falta a essa corrente teórica muitas vezes a capacidade de perceber que técnicos e cientistas podem dispor de prerrogativas próprias e contingenciais de construção de sua autonomia e inserção no campo de atividades correspondente, para além das condições trabalhistas.

Para as vertentes dominantes da Economia da Inovação, por sua vez, o controle da atividade tecnológica é estratégico para o avanço das economias modernas e deve ser cientificamente regulamentado por meio de avaliações de impacto e estudos prospectivos. Um sentido instrumental e direcionado, muitas vezes pouco crítico em termos de reflexão sociológica, pauta essa abordagem operacional da Economia da Inovação. A Sociologia da Ciência adverte para os múltiplos condicionamentos que o contexto da atividade científica impõe aos atores tecnológicos diante dos conflitos do campo e das inúmeras formas de disponibilização de recursos.

Apesar das diferenças, entretanto, é possível perceber uma linha de continuidade entre as diferentes correntes e autores. Nota-se a existência de um contexto de argumentação favorável à redefinição dos parâmetros de abertura para técnicos e pesquisadores impulsionarem as alternativas tecnológicas.

A racionalização e modernização da esfera produtiva é responsável pela imposição de padrões e projeções de resultados 
que não permitem uma abertura às múltiplas demandas coletivas e às aptidões tecnológicas de técnicos e pesquisadores.

Tanto Nathan Rosenberg, um dos grandes expoentes da corrente evolucionista, como o sociólogo Pierre Bourdieu e o filósofo Gilbert Simondon, convergem na identificação de problemas na constituição de sistemas técnicos rotinizados e altamente burocráticos.

Na sociedade tecnológica, o gesto técnico enfrenta uma crise sem precedentes. A percepção dessa crise faz sentido à medida que novas regulamentações e diretrizes tecnológicas são impostas a todos, especialmente aos técnicos. Apesar das diferenças, é preciso atestar que há um conjunto de reflexões que diagnosticam essa crise e suscitam reflexões que precisam ser levadas adiante.

Different approaches to the control and the autonomy of the technological activity in current capitalism

\begin{abstract}
This article aims to discuss the problem of autonomy and control exerted upon technicians in the contemporary world. This question calls for attention to researchers in different fields. Since Marx, sociology of work discusses a crisis of technical gesture combined with a complexification of production systems. Innovation economics points the dilemmas that economic systems face while technicians must attend management determinations. On one hand, the sociology of science has provided much attention regarding the transformations of the scientific field and the many challenges that technicians and experts face in reaching autonomy for their practices. Philosophers of techniques join the debate pointing out an expansion of the technological system mixed with a crisis of technical gesture. In the end, our intention is to show similarities within these trends to understand the problems faced by technical agents.
\end{abstract}

Keywords: technicians; scientists; autonomy; innovation; scientific field; technical gesture. 


\section{Referências bibliográficas}

ANDRADE, Thales. $\mathrm{O}$ problema da experimentação na inovação tecnológica. Revista Brasileira de Inovação, v. 6, n. 2, 2007.

ANTUNES, Ricardo. Adeus ao trabalho. São Paulo: Cortez, 1995.

BOURDIEU, Pierre. O campo cienífico. In: ORTIZ, Renato (Org.) Bourdieu. São Paulo: Ática, 1983.

. Os usos sociais da ciência. São Paulo: Unesp, 2004.

CARDOSO, Adalberto Moreira. Sindicatos, trabalhadores e a coqueluche neoliberal: a era Vargas acabou? Rio de Janeiro: FGV, 1999.

CASSIOLATO, José Eduardo; LASTRES, Helena. Sistemas de Inovação: políticas e perspectivas. Parcerias Estratégicas, n. 8, p. 237-255, 2000

CASTELLS, Manuel. A sociedade em rede, São Paulo: Paz e Terra, 1999.

COTANDA, Fernando. Sindicalismo e inovação tecno-organizacional: a experiência da Central Única dos Trabalhadores. 2001. Tese (Doutorado em Sociologia) - Universidade Federal do Rio Grande do Sul (UFRGS), Porto Alegre, 2001.

DAGNINO, Renato. Ciência e tecnologia no Brasil. Campinas: Unicamp, 2007.

- Neutralidade da ciência e determinismo tecnológico e tecnologia no Brasi. Campinas: Unicamp, 2008.

DODGSON, Mark. As políticas para ciência, tecnologia e inovação nas economias asiáticas de industrialização recente. In: KIM, Liu; NELSON, Richard (Orgs.). Tecnologia, aprendizado e inovação. Campinas: Ed. Unicamp, 2005.

DOSI, Giovanni. Technical change and industrial transformation. London: McMillan, 1988.

FEENBERG, Andrew. Critical theory of technology. Oxford: Oxford University Press, 1991. 
FEENBERG, Andrew. Questioning technology. London: Routledge, 1999.

FREEMAN, Christopher. La teoria económica de la innovación industrial. Madrid: Alianza Editorial, 1975.

GORZ, André (Org.). Crítica da divisão do trabalho. São Paulo: Martins Fontes, 2001.

HABERMAS, Juergen. Ciência e técnica como "ideologia". São Paulo, 1983.

KNORR-CETINA, Karin. La fabricación del conocimiento. Bernal: UNQ, 2005.

KREIMER, Pablo. De probetas, computadoras e ratones. Buenos Aires: Universidad Nacional de Quilmes, 1999.

LATOUR, Bruno. Ciência em ação. São Paulo: Unesp, 2000.

LEMOS, Cristina. Inovação na era do conhecimento.Parcerias Estratégicas, n. 8, p.157-179, 2000.

LAMY, Erwan; SHINN, Terry. L'autonomie scientifique face à la mercantilisation. Actes de la Recherche en Sciences Sociales, n. 164, p. 22-49, 2006.

LOJKINE, Jean. A revolução informacional. São Paulo: Cortez, 1995.

MALLET, Serge. La nouvelle classe ouvriere. Paris: Seuil, 1963.

MARGLIN, Stephen. Origem e funções do parcelamento das tarefas (Para que servem os patrões?). In: GORZ, Andre (Org.). Crítica da divisão do trabalho. São Paulo: Martins Fontes, 2001.

MARTINS, Carlos Estevão Tecnocracia e capitalismo. São Paulo: Brasiliense, 1974.

MERTON, Robert King. Sociologia: teoria e estrutura. São Paulo: Mestre Jou, 1970. 
MOLES, Abraham. Engenheiros e inventores hoje. In: SCHEPS, Ruth. (Org.) O império das técnicas. Campinas: Papirus, 1994.

NELSON, Richard. As fontes do crescimento econômico. Campinas: Unicamp, 2006.

ROSENBERG, Nathan. Por dentro da caixa-preta: tecnologia e economia. Campinas: Unicamp, 2006.

SANIDAS, Elias. Technology, technical and organizational innovations, economic and societal growth. Technology in Society, v. 26, n. 1, p. 67-84, 2004.

SCHUMPETER, Joseph Alois. Capitalismo, socialismo e democracia. Rio de Janeiro: Fundo de Cultura, 1961.

. Teoria do desenvolvimento econômico. São Paulo: Abril, 1982. (Os Pensadores).

SIMONDON, G. Du mode d'existence des objets techniques. Paris: AubierMontaigne, 1969.

STIEGLER, Bernard. Technics and time 1. Stanford: Stanford University Press, 1998.

TRIGUEIRO, Michelangelo Santoro. O clone de Prometeu. Brasília: Ed. UnB, 2002.

ZACKIEWICZ, Mauro. Coordenação e organização da inovação: perspectives do estudo do futuro e da avaliação em ciência e tecnologia. Parceiras Estratégicas, n. 17, p. 193-214, set. 2003. Disponível em: $<$ http://www.cgee.org.br/parcerias/p17.php>. 